\title{
Pharmacists in dispensing drugs (PharmDisp): protocol for a clinical trial to test the effectiveness of distance education in training pharmacists for dispensing drugs
}

\author{
Tiago Marques dos Reis ${ }^{1 *}$, Camilo Molino Guidoni ${ }^{2}$, André Oliveira Baldoni ${ }^{3}$, Edmarlon Giroto $^{4}$, \\ Paulo Roque Obreli Neto ${ }^{5}$, Lorena Rocha Ayres ${ }^{6}$, Leonardo Régis Leira Pereira ${ }^{7}$
}

\begin{abstract}
${ }^{1}$ Department of Clinical and Toxicological Analyzes, Federal University of Alfenas, Alfenas, Minas Gerais, Brazil, ${ }^{2}$ Department of Pharmaceutical Sciences, State University of Londrina, Londrina, Paraná, Brazil, ${ }^{3}$ Department of Pharmacy, Federal University of São João Del-Rei, Divinópolis, Minas Gerais, Brazil, ${ }^{4}$ Department of Pharmaceutical Sciences, State University of Londrina, Londrina, Paraná, Brazil, ${ }^{5}$ Department of Pharmacy, Integrated Colleges of Ourinhos, Ourinhos, São Paulo, Brazil, ${ }^{6}$ Department of Pharmaceutical Sciences, Federal University of Espirito Santo, Vitória, Espirito Santo, Brazil,

${ }^{7}$ Department of Pharmaceutical Sciences, School of Pharmaceutical Sciences of Ribeirão Preto, University of São Paulo, Ribeirão Preto, São Paulo, Brazil
\end{abstract}

\begin{abstract}
Dispensing drug is a moment in which the pharmacist is able to analyze pharmacotherapy and contribute to its rational use. However, research has shown that some pharmacists lack adequate knowledge to perform this service. This study aims to describe a research protocol for a clinical trial to test the effectiveness of a distance learning program to train pharmacists in dispensing drugs. This is a protocol for an open diagnostic, non-randomized, single group clinical trial. A 12-week duration distance learning course was structured on the Moodle platform for training community pharmacists who are registered in the Regional Board of Pharmacy and work as employees or owners in Brazilian community pharmacies. The course curricula involves concepts and practice of dispensing drugs applied to the treatment of hypertension, diabetes mellitus, dyslipidemia and asthma. Pharmacists are divided randomly into groups, to which previously selected tutors give directions to the discussion and clarify questions. A validated questionnaire is being used before and after the course to measure participants' knowledge. Participant satisfaction with the course is also being measured. Pharmacists who work in the study headquarters municipality receive two visits from a mystery shopper, before and after the course, to evaluate their performance in dispensing drugs. The virtual platform and the content of the course material were evaluated by judges. The study has been approved by the Research Ethics Committee of the School of Pharmaceutical Sciences of Ribeirão Preto, University of São Paulo. The sample size was estimated to provide desired power for testing the significance of the difference between baseline-to-endpoint change scores. Information about the course is being released through channels such as social networks. The results will be submitted for publication in scientific journals, but information enabling the identification of the study subjects will be kept confidential. The trial has been registered in The Brazilian Clinical Trials Registry with number RBR7mbrp3 on January 15 ${ }^{\text {th }}, 2015$.
\end{abstract}

Keywords: Pharmacists/distant education. Pharmacists/dispensing of drugs. Pharmacists/continuingeducation.

\section{STRENGTHS AND LIMITATIONS OF THIS STUDY}

- There is a lack of studies in the literature that provide evidence of mechanisms for full control of

\footnotetext{
*Correspondece: T. M. Reis. Departamento de Análises Clínicas e Toxicológicas, Faculdade de Ciências Farmacêuticas, Universidade Federal de Alfenas, Alfenas, Minas Gerais, Brasil. E-mail: tiagomarques_farmacia@yahoo.com.br
}

the evaluation process in distance learning courses in dispensing drugs, avoiding the use of reference materials for performing the activity.

- It was considered that the creation of the course will seek to meet a demand provided by the pharmacists themselves, who are aware of the importance of preparing for the dispensing drugs.

- In the pilot study it was observed that 21 questions allowed us to establish a parameter of comparison between 
the knowledge before and after the intervention, mainly because the questions present common situations in dispensing drugs observed in routine pharmacy practice.

- A systematic evaluation of the learning process was conducted by evaluating both the content and the virtual platform by the judges, and ongoing evaluation of the knowledge of pharmacists by evaluating the activities throughout the training course, the mystery shopper, and the self-reported satisfaction questionnaire, is being conducted, seeking to ensure the internal validity of the study.

- The course that has been developed allows extrapolating this teaching-learning model for other population samples, including those from other countries where the pharmacy-training structure also has gaps, showing the external validity of the research.

\section{INTRODUCTION}

After intensified commercial practices in community pharmacies due to the migration of pharmacists to industrial activity in the last century (Holland, Nimmo, 1999; Pereira, Freitas, 2008; Pereira, Nascimento, 2011) the rescue of clinical activities in these establishments has become one of the major concerns of the institution regulators for the profession in Brazil, such as the Federal Council and Regional Pharmacy Boards. The regulations of clinical practice and pharmacists' prescription, as well as the recognition of community pharmacies as health facilities, are evidence of this process (Conselho Federal de Farmácia, 2013a; 2013b; Brasil, 2014).

Changes in pharmacy education in Brazil have also been observed in recent years. In 2002, for example, a new educational curriculum was established for pharmacy courses, in which the program is characterized by being generic, humanistic, and dedicated to social and integral assistance to health needs (Brasil, 2002). Nevertheless, studies showed that about $80 \%$ of pharmacists working in community pharmacies in Brazil have unsatisfactory or moderate knowledge for dispensing drugs (Reis et al., 2015a; 2015b). Also in Brazil, a study using the mystery shopper technique showed that no pharmacists performed the dispensing of drugs adequately (Obreli-Neto, Baldoni, Guidoni, 2013). In this context, it is worth mentioning that only $10.2 \%$ of Brazilian higher education institutions have disciplines in the areas of Social and Clinical Pharmacy (Oliveira-Sá, 2011). Thus, despite efforts to rescue the pharmacist's responsibility for patient care, this professional has not been prepared to perform drug dispensing properly.

Therefore, community pharmacists need to be trained in relation to the practice of dispensing drugs in order to contribute to the promotion of health and the rational use of medicines. Continuing education (CE) programs can play a vital role in expanding basic pharmacy education and enhancing therapeutic management skills, particularly in areas in which insufficient training has been received or achieved during undergraduate studies (International Pharmaceutical Federation, 2006).

The challenge, however, is to make this qualification possible, since most of the community pharmacists have long working hours, they are paid with values lower than the minimum wage and/or they lack any financial support from the companies they work for to enroll on courses related to patient care activities (Reis et al., 2015a). In these circumstances it becomes crucial to establish innovative strategies to improve the learning process of these professionals.

Internet technology is an emerging option for the provision of distance CE programs because it offers professionals engaged in routine practice the opportunity to continue in the workforce while enrolled in an activelearning environment, allowing them to proceed at their own pace and convenience (Means et al., 2010). This becomes even more relevant in countries such as Brazil, where continental dimensions hinder access to presence-based training courses. Positive results from the use of virtual learning environments are described by various authors (Martín-Blas, Serrano-Fernandéz, 2009; Fernandez-Campos et al., 2010; Mezzari, 2011; Seixas et al., 2012; Diehl et al., 2012; Queiroz et al., 2012), Moodle (Modular Object-Oriented Dynamic Learning Environment) being one of the most used for providing tools to manage the process of teaching and to promote new strategies for learning (Rice, 2008; Scherl, Dethleffsen, Meyer, 2012). Studies show that this system promotes critical and reflective training (Carley, Mackway-Jones, 2007; Bollela, Grec, Matias, 2009; Nuñez et al., 2011; Prado, Vaz, Almeida et al., 2011), but there is no evidence of its use as a continuing education strategy in the improvement of dispensing drugs practice.

Thus, this study aims to describe the research protocol of a clinical trial to test the effectiveness of a distance learning program to train pharmacists in dispensing drugs. The study hypothesis is that a distance training course is able to qualify pharmacists for the clinical activity of dispensing drugs.

\section{METHODS AND ANALYSIS}

\section{Study design}

This is a protocol for an open, non-randomized, 
single grouped, diagnostic clinical trial of which the acronym is Pharmacists in Dispensing Drugs (PharmDisp). It was prepared in accordance with the recommendations of the Standard Protocol Items: Recommendations for Interventional Studies (SPIRIT 2013 Checklist) (Chan et al., 2013). The study has been registered in The Brazilian Clinical Trials Registry with number RBR 7 mbrp3 on January $15^{\text {th }}, 2015$.

For this study, a free online distance course is being offered by the University of São Paulo (USP) to train pharmacists in dispensing drugs. USP (http://www5.usp. $\mathrm{br} /$ english/?lang=en) is a public institution of education recognized through world rankings such as The Times Higher Education and the Webometrics Ranking of World Universities 2015 (University of São Paulo, 2014). Dispensing drugs is defined in Brazil as the act of guidance and provision of medicines, pharmaceutical inputs, and health related products by the pharmacist (Conselho Federal de Farmácia, 2014).

The Moodle course management system is being used as a platform for the course, which was developed by researchers in collaboration with specialist professors in the selected theme, who have an average of ten years experience in research, teaching and/or drug dispensing practice. The administrative, teaching and academic structure of the course can be seen in Figure 1. All necessary resources for the organization and development of the course have been provided by USP and by the National Council for Scientific and Technological Development (CNPq).

\section{Study population and setting}

The study is being conducted with pharmacists working in community pharmacies in Brazil, which are defined as health facilities intended for dispensing and sale of drugs and other pharmaceutical and correlated products in their original package (Brasil, 2014).

\section{Eligibility criteria}

The inclusion criteria for enrolling in the course are pharmacists who: have completed a degree in pharmacy; are registered in the Regional Board of Pharmacy; are employees or owners of community pharmacies.

The Brazilian undergraduate degree in Pharmacy generally lasts five years, during which the students study content related to various areas of pharmaceutical activities (such as community pharmacy, hospital pharmacy, clinical pharmacy, management, industry, and clinical analysis). At least $20 \%$ of the total course workload must be met with supervised training in the possible practice scenarios of pharmaceutical activity. At the end of the graduation the pharmacist must enroll in a Regional Board of Pharmacy

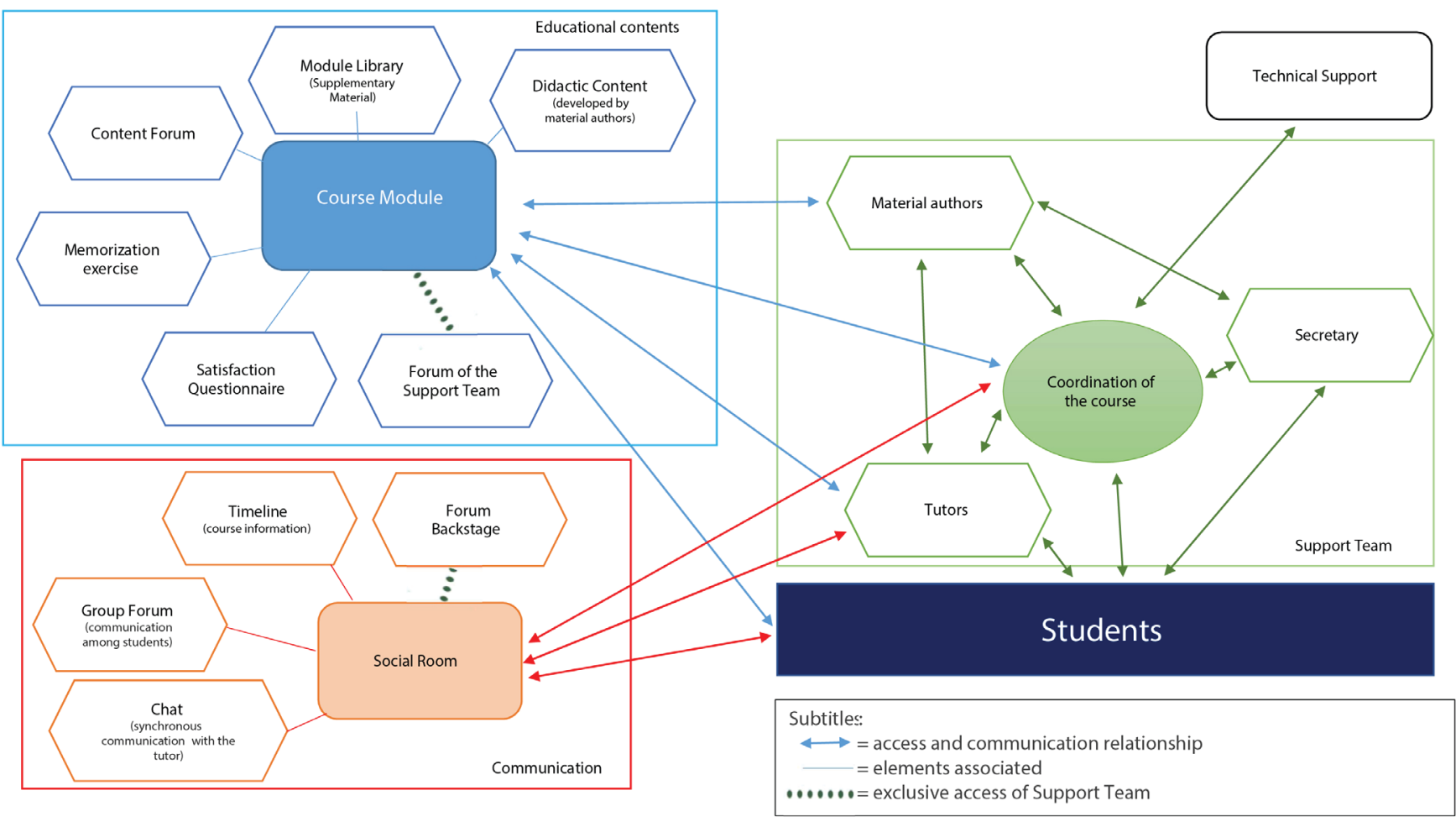

FIGURE 1 - Administrative, didatic and academic struture of Training Course on Dispensing Drugs. 
(the representative board of the profession) to be entitled to exercise the profession (Brasil, 2002).

\section{Interventions}

Pharmacists who meet the inclusion criteria are selected to attend the training course, which has a total workload of 90 hours and must be completed in 12 weeks. There are no face-to-face meetings.

The course content is divided into seven modules in which pharmacists study guidelines of pathophysiology, pharmacological and non-pharmacological treatment and dispensing drugs for some of the most prevalent chronic diseases in Brazil: hypertension, diabetes mellitus, dyslipidemia and asthma (Schmidt et al., 2011; ObreliNeto et al., 2013) (Figure 2).

Furthermore, pharmacists are trained in dispensing antibiotics and over the counter drugs, splitting of manufactured drugs, and health legislation. Thus, the intervention that is being performed meets the recommendations of the American College of Clinical Pharmacy, according to which the clinical training includes knowledge about optimizing pharmacotherapy and health promotion strategies, wellness, and disease prevention by the use of pharmacological and non-pharmacological strategies (American College of Clinical Pharmacy, 2008).

In each module of the course, theoretical case-based material developed by experienced authors is available. This material, after being prepared, was carefully revised by the researchers. Articles, videos and clinical guidelines have also been selected and provided as supplementary study material. In addition, video lessons with an average duration of 10 minutes are recorded with pharmacists presenting their own experiences in dispensing drugs, which fosters learning through audiovisual resources. These pharmacists, chosen by the authors of the didatic content because they are specialists with experience in the accomplishment of pharmaceutical services, were guided by the course coordination team in relation to the development of the video.

Individually, pharmacists have to study all of the available material and then use forums to discuss the subject covered in the module for a predetermined period of time (usually seven days for each discussion). Thus, collaborative learning is being explored as a way to encourage critical thinking and the exchange of experiences and enable the collective construction of knowledge, which are essential elements for the effective empowerment of the study object (Gunawardena, 1992; Hillman, Willis, Gunawardena, 1994; Van-Vliet, Winnips, Brouwer, 2015). Discussions are initiated with guiding questions regarding a medical condition that is presented in the theoretical course material and mediated by tutors.

To retain this knowledge being built collaboratively, exercises are available at the end of each module. The questions are open-ended (when the module involves therapeutics) or multiple choice (when the module involves more conceptual or technical issues) and consist of common situations in the routine practice of community pharmacies with respect to dispensing drugs. Pharmacists have to reflect on their attitude in relation to the situation presented, considering the knowledge obtained in the study of the module.

\section{Evaluation of the virtual platform}

Before the course started, the virtual platform and the content of the course material were evaluated by a panel composed of three professors (judges) who are specialists in the practice of dispensing drugs, and experienced in distance education programs. The evaluated aspects were: layout and platform functionality, clarity and consistency of the offered material, reliability of the information provided, and suitability of the evaluation methods. The evaluation aimed to prove the efficiency of the prepared material and course structure provided via Moodle. The necessary adjustments were made until consensus among the judges was reached.

\section{Tutor's role and selection}

Tutors have the function of monitoring progress of the students on the course, answering questions, proposing reflection of some ideas, practicing communication skills, and mediating discussions taking place in the forums on the subject studied. In addition, they are responsible for submitting motivational messages to the group and encouraging collaborative learning.

Selection of the tutors was made by researchers through analysis of the candidates curriculum. All of them should be pharmacists, prove experience in dispensing drugs, pharmaceutical legislation and knowledge in relation to diseases and treatments covered in the course. Once selected, the tutors underwent 30-day training in which they were oriented in relation to the theoretical content material of the course, the virtual platform use, and mentoring strategies.

\section{Coordination team of the course}

The coordination of the course is composed of the main researcher and his supervisor. Therefore, they lead the other members of the support team (Figure 1). 


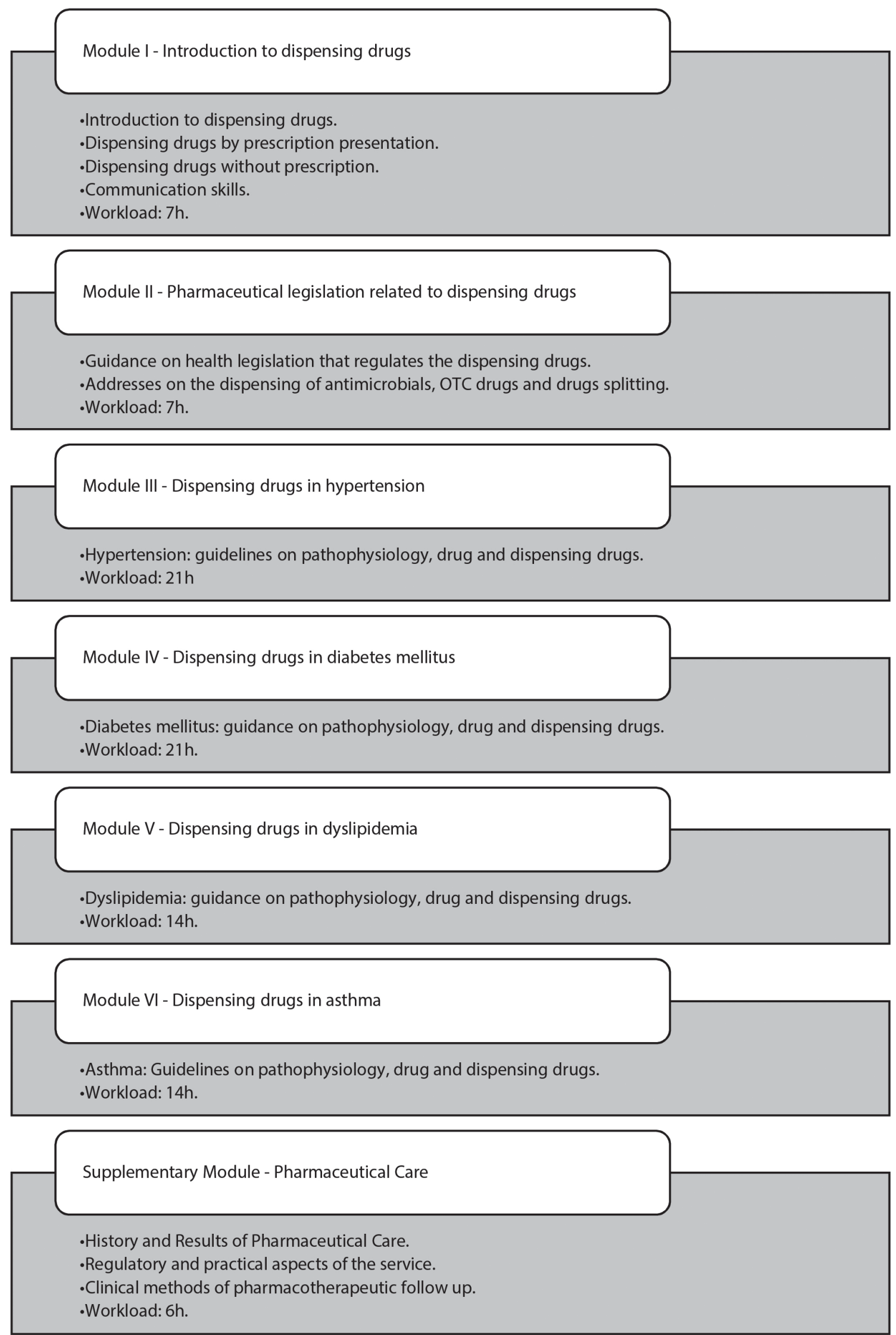

FIGURE 2 - Summary of Training Course on Dispensing Drugs. 
The function of this coordination team is to organize the necessary documentation for the feasibility of the course in USP; to order, monitor and review the theoretical content of the course, including additional materials and educational activities proposed; to structure and program the virtual platform; to establish contact with technical support; to coordinate the work of the secretariat of the course; to manage social networks and carry out the dissemination of the course; to monitor and approve the course applications (according to the established eligibility criteria); to monitor the implementation of the course; to solve student's administrative problems; to recruit, train and monitor the activities of tutors; to evaluate the results of the course in terms of professional's knowledge and satisfaction with the training; and to approve the issuance of certificates of participation. The bureaucratic tasks are performed in collaboration with the secretariat of the course as directed by the principal investigator.

The Backstage Forum (Figure 1) was used for communication between course coordination, authors of the didactic content and tutors on subjects not related specifically to one of the course's modules.

\section{Outcomes}

Kirkpatrick (1994) recommended that the evaluation of CE programs should consist of four levels: learner satisfaction - reaction (level 1), learner outcomes learning (level 2), performance improvement - behavior (level 3), and patient or health outcomes - results (level 4). Therefore this model began with level 1 and sequentially moved throughout the other levels. Each successive level represents a different measure of the effectiveness of $\mathrm{CE}$ programs and increases the clinical significance.

Thus, the primary outcome being considered in this study is pharmacists' knowledge increase for dispensing drugs (learner outcomes - learning). The indicators used to measure this increase are two evaluation tests, one performed before the course starts and another after it ends.

The expected increase in knowledge is of at least $40.0 \%$. Quantification of this percentage was established in the results of a study previously performed by our group (Reis et al., 2015a), since recommendations in relation to this parameter were not found in the literature. In that study, it was found that $50.9 \%$ of the pharmacists achieved an average correct answer of less than half $(43.3 \%)$ of the objective questions, which assessed the level of knowledge of these professionals for dispensing drugs (the satisfactory level of knowledge was obtained when pharmacists reached at least $83.3 \%$ of the questionnaire).
Thus, the difference between the desired level of knowledge $(83.3 \%)$ and the average performance in the study (43.3\%) (Reis et al., 2015a) was defined as the primary endpoint in this study $(40.0 \%)$. It is noteworthy that the selected population was similar in both studies, which allows establishing such an inference about the results.

Secondary outcomes are: pharmacists' satisfaction with the course (learner satisfaction - reaction) and change in professionals' behavior during drug dispensing (performance improvement - behavior). Satisfaction is measured by a satisfaction questionnaire, prepared by the researchers following literature recommendations (Bolliger, 2004; Liaw, Huang, 2013; Kuo et al., 2014) and tested in a pilot study, which is applied at the end of each module. The change in pharmacists' behavior is assessed through the mystery shopper technique (evaluation conducted before the course starts and after it ends) considering the following variables: counseling points, counseling session, and general ability techniques (The American Pharmacist Association, 2013).

For economic and logistical reasons, we did not include Level 4 (Patient or health outcomes - results) of the modified version of Kirkpatrick's Model for Summative Evaluation, and therefore we cannot determine whether our Internet-based CE program is effective at this level.

\section{Sample size}

The sample size $(\mathrm{N})$ was estimated to establish the minimum number of pharmacists needed for the study results to be statistically significant. The sample size was calculated using the formula (Overall, Doyle, 1994):

$$
\mathrm{N}=4\left[\left(\mathrm{z}_{\alpha}+\mathrm{z}_{\beta}\right)^{2}(1-\mathrm{r})\right] /\left[\left({ }_{1}-{ }_{2}\right) / \mathrm{SD}\right] 2
$$

This formula is used to estimate the sample size when the researcher needs to provide desired power for testing the significance of the difference between baselineto-endpoint change scores in two treatment groups. Therefore, we used preliminary estimates of the difference among endpoint means, within-groups error variance (or standard deviation) at cross-section in time, and baselineto-endpoint correlation (Overall, Doyle, 1994):

a) $z_{\alpha}: z$ score beyond which the smaller area under the normal curve is equal to $\alpha$ for a one-sided test or $\alpha / 2$ for a two-sided test. $z_{\alpha=} 2.576$;

b) $z_{\beta}$ : the $z$ score corresponding to a larger area under the curve that is equal to the desired power. $Z_{\beta}=0.842$;

c) 1-r: baseline-to-endpoint correlation. $\mathrm{r}=0.1$;

d) $\left(\bar{x}_{1}-\bar{x}_{2}\right)$ : difference among means. $\left(\bar{x}_{1}-\bar{x}_{2}\right)=83.3$ $-43.3=40 \%$; 
e) SD: standard deviation. $\mathrm{SD}=1.12$.

These data used in the calculation were obtained from a preliminary study (Reis et al., 2015a) performed by our research group relating to the pharmacists' knowledge for dispensing drugs. It is important to note that we did not find in the literature other sources of information for these variables and the sample population is the same for both studies (the preliminary study of Reis et al. and PharmDisp). We adopted $\alpha=1 \%$, with the determination of a minimum sample size of 10 participants.

\section{Recruitment}

Information such as the registration period and how to enroll on the course, as well as the purpose and course content is being released on social networks, in instant messaging applications for mobile devices, on the USP website and in groups that gathered community pharmacists (such as scientific congresses).

In addition, advertising material is being sent by email to all Brazilian Regional Pharmacy Boards, to which we requested the disclosure of the course on their websites and also that course related information should be forwarded by email to the pharmacists registered on the board.

\section{Allocation}

The individuals selected to attend the course are divided into groups using randomization provided by Microsoft ${ }^{\circledR}$ Excel ${ }^{\circledR} 2013$ software without stratification of the sample. The aim of this strategy is to compose the groups that are supervised by each tutor, but all groups receive the same intervention. Randomization is performed by a single investigator.

Legoinha et al. (2006) suggested that each group should receive no more than 30 students and be coordinated by a tutor. However, given the sample loss of up to $70 \%$ observed in epidemiological studies involving the use of the Internet or telephone as a strategy for data collection (Chwastiak et al., 2002; Charani et al., 2013; Shcherbakova, Shepherd, 2014; Frisk et al., 2015), up to 50 participants are allocated to each group.

\section{Participant timeline}

After signing up for the course via the USP virtual system, the selected student has to register in Moodle to be directed to the virtual platform of the course (Figure 3). The course follows a predetermined schedule, and the beginning and end of the modules and
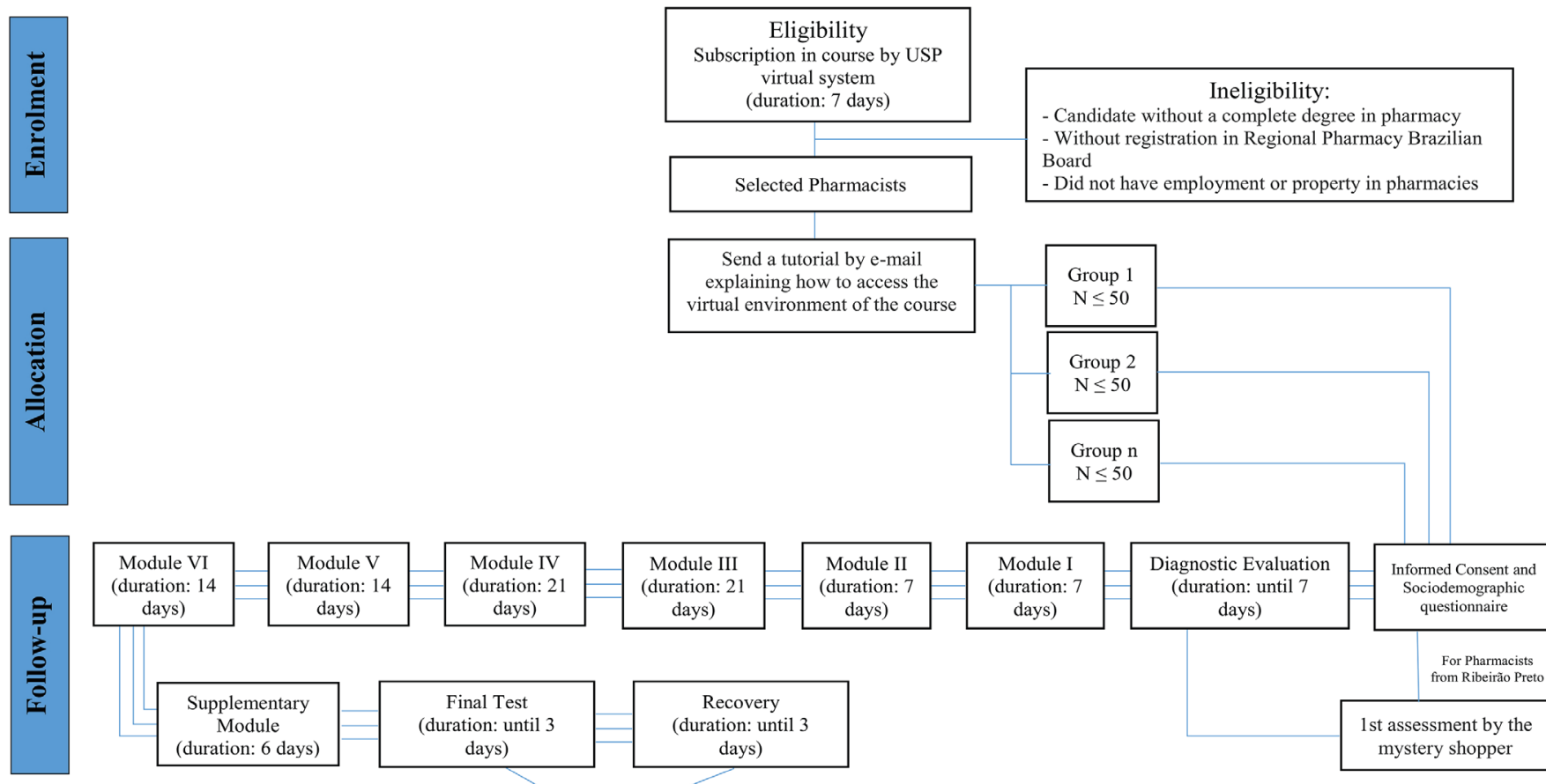
days)

days) Recovery (duration: until 3 days)
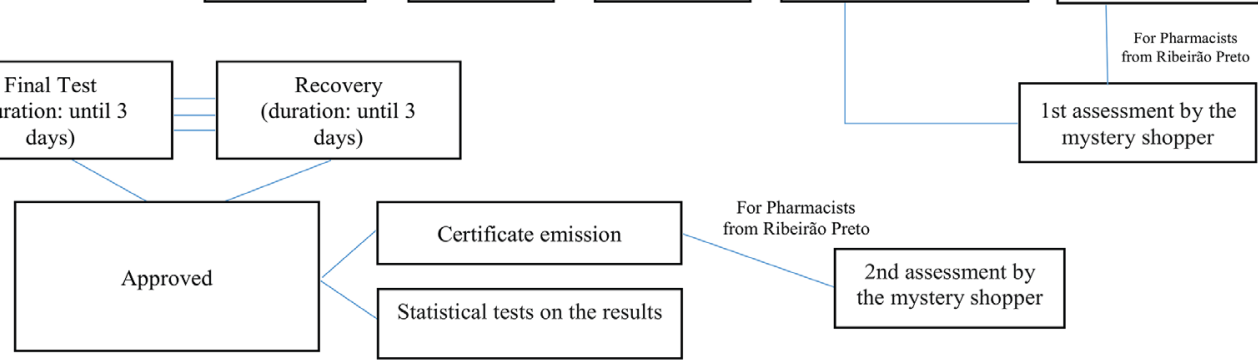

For Pharmacists from Ribeirão Preto

FIGURE 3 - Study design and participant timeline. 
evaluation activities take place at the same time for all participants.

Pharmacists who complete the training course with an average final score greater than or equal to $70 \%$ receive a certificate issued by the Commission for Culture and Extension of the School of Pharmaceutical Sciences of Ribeirão Preto (FCFRP-USP) which is responsible for cultural and social activities provided by the university to the community. The average grade for the final approval was defined following the model adopted by the majority of higher education institutions in Brazil and by the specialization courses, and modality distance training, offered by USP.

With regard to pharmacists unable to complete the course, an email is sent questioning the reasons why they gave up training.

\section{Data collection}

\section{Sociodemographic questionnaire}

A sociodemographic questionnaire answered before the course starts is one of the instruments used to collect data with the following variables: age, gender, place of work (city, state, type of establishment), working conditions (weekly workload, time period with the company, receiving benefits and sales commissions, sources of information about drugs used in the workplace, incentives received from the company to participate in continuing education activities), training (institution and year of completion of the graduation course, activities of continuing education undertaken after graduation), length of experience in dispensing drugs, and difficulties encountered in performing that service.

\section{Diagnostic assessment and final assessment}

Assessment of the pharmacist's knowledge is conducted through a questionnaire applied at two different times: baseline (before the course starts) and endpoint (after the course ends). Thus, it is possible to establish a parameter between pre and post-intervention knowledge. In order to prevent the pharmacists from identifying that the evaluation instrument used both times is the same questionnaire, avoiding response biases, the questionnaires are respectively entitled Diagnostic Assessment and Final Assessment.

For the same reason, the questions and the multiple choice options in both evaluations do not follow the same sequence. It is noteworthy that the period between completion of these assessments (90 days) reduces the chances of memorizing questions and answers. Students do not have access to the answers of the questions.
The evaluation instrument used in the study, prepared by researchers and later validated, consists of 21 multiple-choice questions (three questions offered per module). Each question has five options to be chosen as answers but only one is correct, as recommended (Rattray, Jones, 2007).

The validation process followed models available in the literature (Streiner, Norman, 2008; Pasquali, 2010; Silva et al., 2012; Melo et al., 2015) and began with the analysis of the first version of the questionnaire by five professors (judges) with experience in dispensing drugs, in order to verify the consistency of the content, text cohesion, clarity of the language, existence of ambiguities, level of scientific evidence of the information, and suitability of the questionnaire according to the objectives of the study. Some modifications were suggested and the questionnaire was modified until consensus was reached.

Subsequently, the questionnaire was reviewed by seven experts in dispensing drugs who evaluated the questionnaire according to the same criteria previously described. New modifications were made until consensus among the experts was reached. Thereafter, a pilot study with 62 pharmacists working in dispensing drugs was conducted. From the responses, we calculated Cronbach's alpha to evaluate the internal consistency of the questionnaire, yielding $\alpha=0.81$. Thus, the final version of the questionnaire was obtained, which was classified as validated by the technique of face validity (Gil, 1999; Martins, 2006). Pharmacists who participated in the pilot study will be excluded from the final analysis of the results.

To perform the Diagnostic and Final Assessments, the students access the virtual platform of the course and fill out the online questionnaire. An electronic mechanism (stopwatch) controls the time to perform the assessment (50 minutes), which was estimated during the pilot study.

\section{Satisfaction questionnaire}

The satisfaction questionnaire is composed of the following variables: self-perception of student achievement in the module; self-perception of the knowledge obtained for dispensing drug; satisfaction with the workload of the module; satisfaction with the language used in the teaching materials; satisfaction with the use of the virtual platform; coherence of the evaluation activities with the study content; satisfaction with the theoretical and complementary material available; satisfaction with the tutor; and self-perception of preparedness for drug dispensing after studying the module. Each variable is explored in a different question, in which the response options are: strongly agree, agree, neither agree and nor disagree, disagree and completely disagree. Next to each 
of these options, arranged in a Likert scale, pictograms are placed (facial expressions) to facilitate the expression of the pharmacist's degree of satisfaction with the course.

\section{Mystery shopper}

Assessment by the mystery shopper is performed before and after the pharmacist's participation in the course so that the act of dispensing drug is compared at two different times, demonstrating the knowledge acquired by the professional and the behavioral change. The scenario staged before and after the course is the same, based on clinical situations discussed in the course, but the actor who represents the mystery shopper is different to avoid recognition by the pharmacist being evaluated.

For logistical and financial issues, only pharmacists who work in the headquarters municipality of this study (Ribeirão Preto, São Paulo, Brazil) are being invited to participate in this phase of the research. For the assessment, the pharmacist and the owner (or manager) of the establishment have to sign an Informed Consent Form prior to the visit of the mystery shopper.

The mystery shoppers were trained by the researchers to avoid biases in the survey and they also signed an Informed Consent Form before starting the study. Only the researchers know the identity of the mystery shoppers. The mystery shopper cannot identify themselves as such to the pharmacist, nor any employee or legal representative of the visited establishment.

The entire performance is filmed by a hidden camera that the mystery shopper uses to facilitate and ensure unbiased evaluation. Judgment of the pharmacist's performance will be performed by a panel of three professors (judges) who have a doctorate degree, and experience in dispensing drugs. They will assess the videos and evaluate the service provided by the pharmacist, attributing a grade using a standardized form (The American Pharmacists Association, 2013).

Variables reflecting professional and communication skills will be analyzed, namely: a) information provided (checking, for example, if the pharmacist advised on the medicine to be used, mode of usage, dosage, potential adverse effects, precautions and drug interactions); b) advice (checking, for example, language used and confirm the patient's understanding); and c) communication skills (checking, for example, the order of presentation of facts and concepts, as well as non-verbal communication).

The mystery shopper visits to the community pharmacies occur on weekdays (Monday to Friday) and during business hours (between 08:00 and 18:00 hours). If the pharmacist is not at the establishment, the mystery shopper returns to the pharmacy after a minimum period of three hours and fifty minutes (maximum period of time that a pharmacy can remain without pharmacists, which is acceptable by some Brazilian Regional Pharmacy Boards). The second visit of the mystery shopper occurs at least three months after the end of the course to avoid biases in the evaluation.

\section{Statistical methods}

After course completion, the normality of the sample will be tested by the Shapiro Wilk and KolmogorovSmirnov tests. From the result obtained, the primary outcome will be analyzed through the paired Student $t$ test (if data follows a normal distribution) or Wilcoxon Signed-Rank Sum test (if data does not follow a normal distribution).

Regarding secondary outcomes, participant satisfaction with the course will be analyzed by descriptive statistics (frequencies and means, for example). Additionally, the pharmacist's change in behavior will be analyzed by the chi-square test.

The reported reasons to justify the withdrawal of pharmacists who do not complete the course will also be analyzed by descriptive statistics using numerical summary measures (such as frequency and mean).

The significance level used in the statistical analysis will be $5.0 \%$, and the statistical software Statistical Package for Social Sciences ${ }^{\circledR}$ (SPSS) version 23.0.0 will be used for data treatment.

\section{Ethics and dissemination}

The study has been approved by the Ethics Research Committee of FCFRP-USP, protocol number 1,124,012 and CAAE 20169213.3.0000.5403. The course has also been approved by the Commission for Culture and Extension of FCFRP-USP.

An Informed Consent Form, which presents the objectives of the study and the methodological procedures used in the research, is available on the Moodle platform. After reading the Informed Consent Form, pharmacists must click on the option "I agree to participate voluntarily in this research, in which I will participate in a distance learning course for professional training". It is stated in the document that at the end of the study, participants will receive the results of the research by e-mail.

Personal information collected through the sociodemographic questionnaire is only accessed by a single researcher in order to ensure secrecy and confidentiality of the data provided. Regarding the videos that are recorded during the assessment by the mystery 
shopper, all of them will be destroyed two months after the end of the study and will not be used for any purpose other than the evaluation proposed in this study.

Upon completion of the analysis of the data collected, the results will be submitted for publication in scientific journals. However, information enabling the identification of the study subjects will be kept confidential. Study participants are properly informed about this when they sign the Informed Consent Form.

It is also important to emphasize that a Data Monitoring Committee was not established because this clinical trial has a short duration and known minimal risks. Any modifications to the protocol which may impact on the conduct of the study, potential benefit of the pharmacists or may affect participants' safety, including changes of study objectives, study design, study population, sample sizes, study procedures, or significant administrative aspects will require a formal amendment to the protocol. Such amendment should be approved by the Ethics Research Committee and Commission for Culture and Extension of FCFRP-USP prior to implementation and notified to The Brazilian Clinical Trials Registry.

\section{DISCUSSION}

The study protocols are important tools for the dissemination of information in relation to the development of research projects to avoid duplicity of work. In addition, they serve as a basis for analyzing the scientific merit of proposals sent to development agencies and can encourage collaboration between research groups. In this context, we can affirm that the present study is innovative for some reasons: to establish protocol for a clinical trial involving distance education and drug dispensing; to disseminate information on a clinical trial relating to a particular area of pharmaceutical knowledge; to meet the demand of pharmacists working in community pharmacies, who lack adequate knowledge for dispensing drugs, have a strenuous workload, are paid less than the minimum established, and do not receive support from the establishments where they work to attend training courses (Reis et al., 2015a; 2015b).

It is noteworthy that Brazil has over 70,500 community pharmacies and a population of about 206 million inhabitants (IBGE, 2016). There is one pharmacy for every 3,000 inhabitants, which corresponds to three times more pharmacies than the World Health Organization recommends for developed and developing countries (ZUBIOLI, 1992). These community pharmacies are responsible for $85.6 \%$ of the employments occupied by pharmacists (Zubioli, 1992; Conselho Federal de Farmácia, 2013c), which is justified by the fact that
Brazilian legislation requires the technical assistance of at least one pharmacist throughout all the working hours of the pharmacy (Brasil, 2014). This shows the importance of community pharmacies for the pharmacist workforce, but also reveals that the easy access to pharmacists in these establishments could optimize the health care process for patients in the country if these professionals were more prepared for dispensing drugs.

Thus, we expect that this research protocol can support the implementation of courses for qualification of community pharmacists in order to contribute to the reduction of gaps in the training, and preparation of pharmacists for clinical performance. In addition, the study will generate evidence of the effectiveness of distance learning when establishing a model for training courses and defining instruments for the systematic evaluation of professionals in virtual learning environments, which was not found in the literature until now. It is worth mentioning that the internal consistency coefficient attested the validity of the knowledge measurement instrument (Diagnostic Assessment/Final Assessment), since questionnaires in the development phase must present $\alpha>0.70$ (Alexandre et al., 2013; Shcherbakova, Shepherd, 2014).

In addition, as proposed by Troncon (2007), the use of a mystery shopper enables a technically more suitable judgment to verify the pharmacist's learning, checking their performance at a level of appropriate and homogeneous complexity. It is important to highlight that the use of a questionnaire to evaluate professional practice allows the knowledge that the pharmacists are being evaluated, and this can alter their performance during the test, yielding results that do not express what actually happens in the practice setting (Howthorne effects) (The Joint Commission, 2009). Therefore, the mystery shopper method is helpful in order to overcome these methodological problems, and it shows to be a useful and objective tool for evaluating professional performance.

The authors acknowledge that carrying out the mystery shopper exclusively in the headquarters municipality of this study may undermine the statistical inference of the results, but it is necessary to consider the logistical and financial constraints for this research. In addition, the protocol systematizes the performance of the clinical trial but does not present the results of the proposal, and it is necessary to wait until the collection and analysis of the data to increase the level of knowledge in the specific area of this study.

\section{CONCLUSION}

This protocol has defined models for structuring an online distance learning course to train pharmacists in 
dispensing drugs, until now not available in the literature. The definition of this model establishes criteria for the qualification of dispensing drugs, which promotes the rational use of medicines and brings benefits to public health. Thus, this study will be able to provide the development of new research and strategies for the improvement of pharmacist training, especially in a context where the workload and salary received interfere with this process.

\section{AKNOWLEDGEMENTS}

Ribeirão Preto Information Technology Center (CeTI-RP) for offering technical support to the online course. FCFRP-USP for providing conditions for the course to be conducted within the institution. The National Council for Scientific and Technological Development $(\mathrm{CNPq})$ for funding. To the tutors for collaborating in the mentoring process of the course. We thank John Carpenter, Ribeirão Preto, SP, Brazil, for the English language revision.

\section{FUNDING}

This research received funding from the National Council for Scientific and Technological Development. This funding source had no role in the design of this study and will not have any role during its execution, analyses, interpretation of the data, or decision to submit results.

\section{COMPETING INTERESTS} interests.

The authors declare that they have no competing

\section{REFERENCES}

Alexandre NMC, Gallasch CH, Lima MHM, Rodrigues RCM. Reliability in the development and evaluation of measurement instruments in the health field. Rev Eletron Enf. 2013;15(3):802809.

American College of Clinical Pharmacy. The definition of Clinical Pharmacy. Pharmacotherapy. 2008;28(6):816-7.

Bollela VR, Grec W, Matias AA. Shortening distances: a Moodle platform supports programme evaluation in internship. Med Educ. 2009;43(11):1114-5.

Bolliger, DU. Key factors for determining student satisfaction in online courses. Int J E-learning. 2004;3(1):61-67.
Brasil. Conselho Nacional de Educação. Camera de Educação Superior. Resolução n $2 / 2002$. Brasília: Diário Oficial da União; 2002.

Brasil. Lei n. ${ }^{\circ}$ 13021/2014. Dispõe sobre o exercício e a fiscalização das atividades farmacêuticas.. Brasília: Diário Oficial da União; 2014.

Carley S, Mackway-Jones K. Developing a virtual learning course in emergency medicine for doctors. Emer Med J. 2007;24(8):525-8

Chan A-W, Tetzlaff JM, Altman DG, Laupacis A, Gøtzsche PC, Krleža-Jerić K, et al. SPIRIT 2013 statement: defining standard protocol items for clinical trials. Ann Intern Med. 2013;158(3):200-7.

Charani E, Kyratsis Y, Lawson W, Lawson, Wickens H, Brannigan ET, Moore LS, Holmes AH. An analysis of the development and implementation of a smartphone application for the delivery of antimicrobial prescribing policy: lessons learnt. J Antimicrob Chemother. 2013;68(4):960-7.

Chwastiak L, Ehde DM, Gibbons LE, Sullivan M, Bowen JD, Kraft GH. Depressive symptoms and severity of illness in multiple sclerosis: epidemiologic study of a large community sample. Am J Psychiatry. 2002;159(11):1862-8.

Diehl LA, Gomes CP, Sary GV, Rocha HCG, Camargo LMA, Gordan PA. Distance education in nephrology in the Amazon region: processes and results. Rev Bras Educ Med. 2012;36(4):550-6.

Conselho Federal de Farmácia. Resolução n. ${ }^{\circ}$ 585/2013. Regulamenta as atribuições clínicas do farmacêutico e dá outras providências. Brasília: Diário Oficial da União; 2013a.

Conselho Federal de Farmácia. Resolução n. ${ }^{\circ}$ 586/2013. Regula a prescrição farmacêutica e dá outras providências. Brasília: Diário Oficial da União; 2013 b.

Conselho Federal de Farmácia. I Oficina sobre Assistência Farmacêutica em Farmácias Comunitárias. Conselho Federal de Farmácia; 2013c.

Conselho Federal de Farmácia. Resolução n. ${ }^{\circ}$ 357/2001. Aprova o regulamento técnico das Boas Práticas de Farmácia. Brasília: Brasília: Diário Oficial da União; 2014. 
Fernández Campos F, Colom Codina H, Clarés Naveros B, Calpena Campmany AC. Self-learning of biopharmacy and pharmacokinetic computer software. Ars pharm. 2010;51(supl. 2):290-5.

Frisk PB, U F Kalvemark-Sporrong, S Kalvemark-Sporrong, S. Exploring community pharmacists' experiences of surveying patients for drug utilization research purposes. Int J Clin Pharm. 2015;37(3):522-8.

Gil AC. Pesquisa social. 5 ed. Sao Paulo:Atlas; 1999.

Gunawardena CN. Changing faculty roles for audiographics and online teaching. Am J Distance Educ. 1992;6(3):58-71.

Hillman DC, Willis DJ, Gunawardena CN. Learner-interface interaction in distance education: An extension of contemporary models and strategies for practitioners. Am J Distance Educ. 1994;8(2):30-42.

Holland RW, Nimmo CM. Transitions, part 1: beyond pharmaceutical care. Bethesda: Am J Health Syst Pharm. 1999. p. 1758-64.

Instituto Brasileiro de Geografia e Estatística. IBGE. Projeção da população do Brasil e das Unidades da Federação. [citado 24 out 2016]. Disponível em: http://www.ibge.gov.br/apps/ populacao/projecao/.

International Pharmaceutical Federation. FIP. Global Pharmacy Workforce and Migration Report; 2006.

Kirkpatrick D. Evaluating training programs: the four levels. San Francisco: Berrett-Koehler; 1994.

Kuo YC, Walker AE, Schroder KE, Belland BR. Interaction, Internet self-efficacy, and self-regulated learning as predictors of student satisfaction in online education courses. Int High Educ. 2014;20:35-40.

Legoinha P, Pais J, Fernandes J, editors. Moodle and virtual learning communities. Portugal: VII National Congress of Geology; 2006.

Liaw SS, Huang HM. Perceived satisfaction, perceived usefulness and interactive learning environments as predictors to self-regulation in e-learning environments. Comp \& Educ. 2013;60(1):14-24.
Martín-Blas T, Serrano-Fernández A. The role of new technologies in the learning process: Moodle as a teaching tool in Physics. Comput Educ. 2009;52(1):35-44.

Martins GA. Reliability and validity. Rev Bras Gestão Negoc. 2006;8(20):1-12.

Means B, Toyama Y, Murphy R, Bakia M, Jones K. Evaluation of evidence-based practices in online learning: a meta-analysis and review of online learning studies. Washington: U.S. Department of Education; 2010.

Melo MCB, Falbo Neto GH, Alchieri JC, Figueiroa JN. Scale for assessment of aggressive behavior of adolescents. Cienc Saude Colet. 2015;20(6):1861-8.

Mezzari A. The use of Problem-Based Learning (PBL) as reinforcement for students using the moodle learning environment. Rev Bras Educ Med. 2011;35(1):114-21.

Núñez JC, Cerezo R, Bernardo A, Rosário P, Valle A, Fernández $\mathrm{E}$, et al. Implementation of training programs in self-regulated learning strategies in Moodle format: results of a experience in higher education. Psicothema. 2011;23(2):274-81.

Obreli-Neto PR; Baldoni AO, Guidoni CM. Pharmacotherapy: therapeutic guideline for the most prevalent diseases. 1 ed. São Paulo: Pharmabooks; 2013.

Obreli-Neto PR, Pereira LRL, Guidoni CM, Baldoni AO, Marusic S, Lyra-Junior DP, et al. Use of simulated patients to evaluate combined oral contraceptive dispensing practices of community pharmacists. PLoS One. 2013;8(12):e79875.

Oliveira-Sá AD. Evaluation of curriculum matrices of undergraduate courses in pharmacy from the Brazilian federal universities. Aracaju: Work Degree Completion of course in Pharmacy - Department of Physiology, Pharmacy School, Federal University of Sergipe; 2011.

Overall JE, Doyle SR. Estimating sample sizes for repeated measurement designs. Control Clin Trials. 1994;15(2):100-23.

Pasquali L. Psychological instrumentation: fundamentals and practical. Porto Alegre: Artmed; 2010.

Pereira LRL, Freitas O. The evolution of pharmaceutical care and the prospect for the Brazil. Braz J Pharm Sci. 2008;44(4):601-612. 
Pereira ML, Nascimento MMG. From the apothecary to pharmaceutical care: perspectives of the pharmacist. Rev Bras Farm. 2011;92(4):245-252.

Prado C, Vaz DR, Almeida DM. Theory of meaningful learning: design and virtual classroom assessment in Moodle. Rev Bras Enf. 2011;64(6):1114-21.

Queiroz FM, Aroldi JBC, Oliveira GDS, Peres HHC, Santos VLCG. Venous ulcer and compression therapy for nurses: development of online course. Acta Paul Enf. 2012;25(3):435440 .

Rattray J, Jones MC. Essential elements of questionnaire design and development. J Clin Nurs. 2007;169(2):234-43.

Reis TM, Guidoni C, Girotto E, Rascado RR, Mastroianni P, Cruciol J, et al. Knowledge and conduct of pharmacists for dispensing of drugs in community pharmacies: a cross-sectional study. Braz J Pharm Sci. 2015a;51(3):733-744.

Reis TM, Rocha KS, Barros I, Santos L, Paixao FP, Almeida $\mathrm{FH}$, et al. Pharmacists' skills in conducting clinical services in community pharmacies in urban areas of Northeast Brazil. Lat Am J Pharm. 2015b;34(4):725-31.

Rice W. Moodle 1.9 e-learning Course development: a complete guide $t$ successful learning using Moodle. $1^{\text {st }}$ ed. Birmingham: Packt Publishing; 2008.

Scherl A, Dethleffsen K, Meyer M. Interactive knowledge networks for interdisciplinary course navigation within Moodle. Adv Physiol Educ. 2012;36(4):284-97.

Schmidt MI, Duncan BB, e Silva GA, Menezes AM, Monteiro CA, Barreto SM, et al. Chronic non-communicable diseases in Brazil: burden and current challenges. Lancet. 2011;377(9781):1949-61.

Seixas CA, Mendes IA, Godoy S, Mazzo A, Trevizan MA, Martins JC. Virtual learning environment: script structure of an online course. Rev Bras Enf. 2012;65(4):660-6.
Shcherbakova N, Shepherd M. Community pharmacists, Internet and social media: an empirical investigation. Res Social Adm Pharm. 2014;10(6):e75-85.

Silva PR, Araújo ES, Caldeira AMA, Carvalho GS. Construction and validation of a questionnaire for analysis of bioethical concepts. Rev Bioetica. 2012;20(3):488-99.

Streiner DL, Norman GR. Health measurement scales: a practical guide to their development and use. 4 ed. Oxford University Press; 2008.

The American Pharmacist Association. The art of patient counseling. Washington: APA; 2013.

The Joint Commission. Measuring hand hygiene adherence: overcoming the challenges. Oakbrook Terrace, Illinois: The Joint Commission; 2009.

Troncon LEA. Utilização de pacientes simulados no ensino e na avaliação de habilidades clínicas. Medicina (Ribeirao Preto Online). 2007;40(2):180-91.

University of São Paulo. 80 years of excelence São Paulo: USP; 2014. [cited 22 Oct 2015]. Available from: http://www5.usp.br/ institucional/a-usp/historia/.

Van Vliet EA, Winnips JC, Brouwer N. Flipped-class pedagogy enhances student metacognition and collaborative-learning strategies in higher education but effect does not persist. CBE Life Sci Educ. 2015;14(3):1-10.

Zubioli A. Profissão: farmacêutico. E agora? Curitiba: Lovise; 1992. p. 48.

Received for publication on $30^{\text {th }}$ November 2016 Accepted for publication on $01^{\text {st }}$ September 2017 